\title{
Traffic Crash Victimizations of California Children and Teenagers by Drinking Over-21 Drivers
}

\author{
Mike Males, Ph.D. \\ Center on Juvenile and Criminal Justice; YouthFacts.org
}

\begin{abstract}
"Underaged drinking" by Californians younger than 21 generates perpetual concern, but the toll "overaged drinkers" 21 and older inflict on children and teenagers has not been quantified. This study extracts Fatality Analysis Reporting System crash cases involving California drivers testing positive for alcohol use along with those of the other drivers, passengers, and nonoccupants in the same crashes for 1998-2007 and arranges them in cross tabulations showing the ages of drinking drivers in fatal crashes by ages, injury severity, and types of victims. National Highway Traffic Safety Administration estimates are used to project all alcohol-related traffic victimizations. Californians age 21 and older who drank and drove caused approximately 235,000 crashes from 1998-2007 victimizing persons under age 20, killing more than 400 children under age 16 and 400 teens age 16-19 and injuring nearly 80,000 children and teens. Drinking over-21 drivers caused most alcohol-related victimizations of teenage vehicle passengers and nonoccupants and victimized more sober teenage drivers than drinking teen drivers victimized sober over-21 drivers. If tabulated as a separate mortality cause, "overaged drinking and driving" would be the fifth leading cause of death to California teens age 16-19 and the sixth leading cause for children ages 115. The findings suggest "overaged drinking" represents as severe a hazard to teenagers as "underaged drinking."
\end{abstract}

(c) 2009 Californian Journal of Health Promotion. All rights reserved.

Keywords: adolescents, alcohol, motor vehicle, mortality, injury

\section{Introduction}

"Underaged drinking" by Californians younger than 21 years of age is a perpetual target of public policy, official, safety program, and news media campaigns (e.g., California Highway Patrol, 2009; AAA, 2006; InjuryBoard, 2006). However, the risks of "overaged drinking" (that is, alcohol consumption by persons age 21 and older) to children and teenagers receives little notice. This is puzzling, since in many respects underaged and overaged drinking are strongly interrelated behaviors.

For examples, at the family level, parents who drink alcohol are much more likely than nondrinking parents to have children who drink (Latendresse, Rose, Viken, et al, 2008; NCASA, 1999; Hawkins, Graham, and Maguin, 1997; NCASA, 1997). At the state level, National Household Survey on Drug Use and Health
(SAMHSA, 2009) tabulations show drinking and binge drinking rates among adults are strongly correlated with those of teenagers. For example, this author's analysis of surveys for the 1999-2006 period shows strong correlations between teen (age 12-17) and adult (age 26 and older) rates of alcohol use ( $\mathrm{r}=0.77, \mathrm{p}<0.0001,49$ df) and binge drinking $(r=0.78, p<0.0001)$ by state. Correlations between changes from 1999 to 2006 in states' rates of teen and adult drinking $(\mathrm{p}=0.47, \mathrm{r}<0.001)$ and binge drinking $(\mathrm{r}=0.58$, $\mathrm{p}<0.0001)$ are also strong. Similarly, using National Highway Traffic Safety Administration (NHTSA, 2007) estimates of driver involvements in alcohol-related fatal crashes by state to standardize Fatality Analysis Reporting System (FARS, 2009) tabulations of alcoholrelated fatal crashes, the correlations between state-by-state rates for teen drivers age 16-19 and rates for adult drivers age 21 and older are very strong $(\mathrm{r}=0.81, \mathrm{p}<0.0001,49 \mathrm{df})$. 
Likewise, rates of fatal crashes involving drinking drivers ages 15-19 and ages 20 and older per 100 million miles driven by county for 1994-2007 (see Males, 2009, for method) also are powerfully correlated for California's 36 most populous counties $(\mathrm{r}=0.84, \mathrm{p}<0.0001,34$ df). Correlation does not prove causality, of course. The most conservative interpretation of these strong and consistent correlations across an array of measures is simply that where and when adults drink more, drink heavily, and cause traffic crashes after drinking, teens also drink more, drink heavily, and cause crashes after drinking.

This paper explores a related health topic that has received little systematic attention: the extent to which intoxicated adult drivers older than 21 kill, injure, and otherwise victimize children and teenagers. In official and media depictions, the deaths of approximately 125 California teenagers and the injury of around 3,000 more every year in alcohol-related traffic crashes uniformly are blamed on teenagers' drinking and driving (e.g., California Highway Patrol, 2009). However, other than occasional news stories of individual accidents, there appears remarkably little discussion of the general issue of drinking adults as a group victimizing teenagers.

This study attempts to quantify one definable part of this phenomenon: the fatality, injury, and noninjury victimization toll inflicted on California teens age 16-19 and younger youths and children by adult drivers age 21 and older who were involved in fatal crashes and who tested positive for alcohol use. Several papers have reported that a large majority of drinking drivers involved in crashes that killed approximately 400 U.S. children under age 16 every year were adults old enough to be their parents or caregivers (Margolis, Foss, \& Tolbert, 2000; Shults, Lindsey, \& Quinlan, 2002), but no systematic estimates of the toll to both children and teenagers appears available. The hypothesis of this paper reflects straightforward assumptions about risk exposure: the large majority of victims of alcohol related crashes who are under age 16 or age 21 and older would be victimized by intoxicated adult drivers age 21 and older, while the large majority of victims age 16-19 would be victimized by intoxicated peers.

\section{Method}

\section{Data}

Testing this hypothesis requires an unbiased tabulation or sampling of the ages of each intoxicated driver involved in a motor vehicle crash along with the ages of each victim in these same crashes. The most comprehensive tabulation appears to be by the US Highway Traffic Safety Administration's Fatality Analysis Reporting System (FARS, 2009), which provides details on each traffic crash causing at least one fatality on public roadways in the United States. The variables extracted for this analysis from the file's case listings (which are taken from law enforcement accident records) include:

- the year of the crash for 1998 through 2007;

- the age, state of residence, alcohol test result, injury severity, driver's license status, and previous drunken driving conviction status of each motor vehicle driver;

- the age and injury severity for passengers, cyclists, pedestrians, and other nonoccupants of vehicles; the number and type (driver, passenger, nonoccupant) of each person in the crash; and

- the number of vehicles in each crash.

Population estimates by age, state, and year were available from the California Department of Finance and Bureau of the Census (2009).

\section{Analysis}

The annual case number of each fatal accident was extracted from the FARS (2009) online encyclopedia file for the 1998-2007 period and converted to a unique accident case number by adding state and year values. The accident case numbers in which at least one driver had a tested blood alcohol content (BAC) of $0.01 \%$ or higher and the small number in which the driver refused to take an alcohol test ("alcohol test result" coded 1 through 95 by FARS) were selected for this study. The data abstraction selected only those cases involving intoxicated 
drivers residing in California and excluded crashes involving non-California drivers and California crashes in which all drivers were sober.

This selection yielded a cross-section of 10,048 California drivers involved in 9,080 fatal crashes over the 10-year period whose tested BAC was $0.01 \%$ or higher (in $7 \%$ of these crashes, more than one driver tested positive for alcohol use). These crashes resulted in 24,238 victims, $45.7 \%$ of whom were killed, $37.8 \%$ of whom were injured, and $16.5 \%$ of whom were uninjured or suffered unknown injuries. Motor vehicle drivers comprised $57.8 \%$ of the victims of these accidents; passengers, 39.3\%; and cyclists, pedestrians, and other vehicle nonoccupants, $2.8 \%$. The average BAC of drinking drivers was $0.154 \%$, with a median BAC of $0.143 \%$, considerably above the level of $0.08 \%$ used as the legal standard establishing driver intoxication.

The accident case number for each drinking driver was matched to that of every other vehicle driver, passenger, and nonoccupant involved in the same accident to determine the total number of victims by age and injury severity. The victims of each accident were assigned to the intoxicated driver presumed at fault for the accident. In the $7 \%$ of alcohol-related fatal crashes in which more than one driver had been drinking, each drinking driver was coded as at fault; that is, in a two-car crash involving two drinking drivers, each driver was assigned responsibility for all victims of the accident, including the other driver. Figures for age 20, which represents both an "underaged drinking" and a non-teen-age category, are shown separately in the tables and are not included in the matrices comparing teenage and over- 21 age groups.

Some potential complications are caused by population and law changes that might have affected the proportions of teenagers involved in crashes. From 1998 to 2007, teens age 16-19 as a proportion of the population of ages 16 and older fell from $7.8 \%$ to $7.6 \%$ and the proportion of all licensed drivers who were aged 16-19 rose from $3.9 \%$ to $4.1 \%$. California's graduated driver licensing laws and other age-based restrictions applied to under-18 drivers over the study period may have reduced driving, teenage passenger conveyance, and fatal crashes by 16 year-olds relative to older age groups, though recent studies argue these were more than offset by increases in crashes involving 18-year-olds (Masten and Hagge, 2004; Males, 2007). In any case, the number of California teenagers victimized in fatal alcohol-related crashes (around 300 per year) and the proportion victimized by other teenaged drivers (about half) both stayed relatively stable over the 10-year period. It also may be argued that low BACs, say $0.01 \%$, would not impair most drivers, only those with very low tolerance for alcohol. However, this paper uses BAC results from alcohol tests that occur some time after the crash; a tested result of $0.01 \%$ implies a higher BAC at the time of the crash. BACs of $0.02 \%$ and higher have been linked to higher crash risk for drivers of all ages (Zador, Krawchuk, \& Voas, 2000).

The cross-sectional tabulation of all persons involved in fatal alcohol-related crashes in California for 1998-2007 by age, injury severity, and person type were then arranged in matrixes to show the age of each intoxicated driver in a crash by the age(s) of each victim in the same crash. Tables 1 and 2's matrixes show intoxicated-driver age group by age group of victim, categorized by injury severity (fatal injury, nonfatal injury, noninjury/unknown injury) and person type (vehicle driver, passenger, nonoccupant). Table 3 compares the number of teens ages 16-19 who were victimized by drinking adult drivers ages 21 and older with the opposite configuration, adults victimized by drinking teen drivers. Table $3 \mathrm{a}$ repeats Table 3's comparison but only for "innocent" victims (that is, victims who were sober drivers, sober cyclists and pedestrians, or vehicle passengers regardless of sobriety); the idea is to exclude drinking drivers who victimize themselves as well as other driver and nonoccupant victims whose own drinking may have contributed to their victimizations.

Clearly, over-21 drivers would cause more total accidents than teen drivers because there are 
more adult drivers, particularly licensed ones, who drive more miles on average compared to teens. However, in terms of predicting interage victimization patterns for alcohol-related crashes, this expectation is complicated by several factors. First, normal patterns of agepeer associations mean that drivers are disproportionately likely to victimize people near their age (especially since drinking drivers first of all victimize themselves), a supposition accident patterns confirm for every age group except those under age 16 (see Tables 1, 2). Second, licensed-driver tabulations are of questionable validity in determining normal probabilities by age of causing an alcoholrelated crash, since $26 \%$ of drivers in fatal crashes testing positive for alcohol were unlicensed compared to $12 \%$ of drivers who test negative. Third, the usual measure of traffic crash involvement exposure, vehicle miles driven, does not apply to alcohol-related crashes; the real risk factor would be "vehicle miles driven after drinking," an index that cannot be reliably estimated from existing sources. These complications mean that normal population, licensed driver, and miles-driven proportions represent dubious standards to estimate the probabilities of within-age and between-age accident victimizations. Therefore, it is difficult to predict "expected" frequencies of teenage victimization by adult drinking drivers (and vice versa) to compare to observed frequencies. Only one expected reciprocity can be tested using consistent populations: drivers' victimizations of other drivers by age group. Under normal population proportion assumptions, we would expect the number of teen drivers victimized by drinking adult drivers to be equivalent to the number of adult drivers victimized by drinking teen drivers (see Tables 3, 3a).

This paper's approach produces minimum numbers. The overall toll of fatal, injury, and noninjury victimizations of children and teens by drinking adult drivers (and vice versa) is much higher than just the fatal-crash tabulations involving alcohol-tested drinking drivers would produce. Alcohol test results are available for only $47.9 \%$ of California drivers involved in fatal crashes for the 1998-2007 period and even less so for drivers in injury and noninjury crashes. NHTSA's (2001) imputation based on accident records estimates that California's true toll in 2000 if every driver had been tested would be 1,060 drinking drivers involved in fatal crashes that killed 1,401 people, considerably higher than FARS tabulations of alcohol-tested cases (901 drinking drivers, 1,024 fatalities) and California Highway Patrol reports (912 drinking drivers, 1,233 fatalities).

Overall, the crash totals used in this study constitute only around $1 \%$ of all alcohol-related traffic accidents, according to two estimations (NHTSA, 2001; PIRE, 2000). In an effort to approximate true tolls, NHTSA and Pacific Institute for Research and Evaluation (PIRE) imputations of total alcohol-related crashes are used as multipliers to adjust the FARS alcoholtest tabulations upward. Author calculations based on PIRE (2000) imputations project that alcohol-related crashes cause approximately 1.37 times more fatal, 50.2 times more injury, and 81 times more total crashes (including noninjury ones) in California than are captured in FARS fatal-crash tabulations of drivers with measured blood alcohol contents (Table 4). NHTSA's (2001) estimates of driver involvements in alcohol-related crashes indicate that California accounts for about $8.4 \%$ of the nation's alcohol-related traffic victimizations. These estimates of all alcohol-related victimizations, shown in Table 4 , should be seen as rough estimates, especially for noninjury crashes.

\section{Results}

\section{Fatal crash tabulations}

Over the 1998-2007 period, FARS cases list 1,600 California children under age 16 and 1,300 California teenagers age 16-19 victimized in fatal crashes involving drivers age 21 and older whose alcohol tests confirmed drinking. Of these, 296 children and 307 teens were killed, 848 children and 725 teens were injured, and 454 children and 270 teenagers experienced no or unknown injuries (Table 1). The blood alcohol content (BAC) of drivers age 21 and older involved in alcohol-related fatal crashes 
Table 1

Age group of drinking driver in fatal crash by age group of victim and injury severity, California, 1998-2007

\begin{tabular}{|c|c|c|c|c|c|c|c|c|c|}
\hline \multirow{2}{*}{$\begin{array}{c}\text { Victim } \\
\text { age }\end{array}$} & \multicolumn{9}{|c|}{ Intoxicated driver age } \\
\hline & $<20$ & 20 & $21-24$ & $25-34$ & $35-44$ & $45-54$ & $55-64$ & $65+$ & Total \\
\hline \multicolumn{10}{|c|}{ All victimizations in fatal crashes } \\
\hline $0-9$ & 40 & 19 & 115 & 371 & 239 & 100 & 58 & 24 & 966 \\
\hline $10-15$ & 146 & 29 & 98 & 231 & 217 & 96 & 34 & 15 & 866 \\
\hline $16-19$ & 1,531 & 175 & 448 & 390 & 273 & 104 & 55 & 32 & 3,008 \\
\hline 20 & 113 & 500 & 161 & 119 & 60 & 30 & 14 & 5 & 1,002 \\
\hline $21-24$ & 205 & 144 & 2,461 & 645 & 242 & 129 & 70 & 16 & 3,912 \\
\hline $25-34$ & 203 & 76 & 550 & 3,818 & 488 & 245 & 146 & 75 & 5,601 \\
\hline $35-44$ & 115 & 67 & 282 & 624 & 2,525 & 298 & 156 & 62 & 4,129 \\
\hline $45-54$ & 94 & 34 & 187 & 404 & 352 & 1,514 & 115 & 49 & 2,749 \\
\hline $55-64$ & 38 & 25 & 91 & 167 & 145 & 109 & 588 & 42 & 1,205 \\
\hline $65+$ & 22 & 22 & 41 & 121 & 130 & 94 & 41 & 329 & 800 \\
\hline Total & 2,507 & 1,091 & 4,434 & 6,890 & 4,671 & 2,719 & 1,277 & 649 & 24,238 \\
\hline \multicolumn{10}{|c|}{ Fatalities } \\
\hline $0-9$ & 10 & 6 & 22 & 82 & 53 & 14 & 6 & 1 & 194 \\
\hline $10-15$ & 44 & 10 & 22 & 36 & 37 & 15 & 7 & 1 & 172 \\
\hline 16-19 & 717 & 61 & 128 & 91 & 47 & 26 & 10 & 5 & 1,085 \\
\hline 20 & 26 & 279 & 57 & 33 & 15 & 10 & 4 & & 424 \\
\hline $21-24$ & 63 & 46 & 1,396 & 203 & 60 & 20 & 8 & 2 & 1,798 \\
\hline $25-34$ & 62 & 28 & 183 & 2,204 & 126 & 49 & 28 & 7 & 2,687 \\
\hline $35-44$ & 30 & 19 & 100 & 198 & 1,626 & 73 & 27 & 12 & 2,085 \\
\hline $45-54$ & 30 & 9 & 58 & 129 & 122 & 1,106 & 27 & 8 & 1,489 \\
\hline $55-64$ & 13 & 12 & 34 & 50 & 55 & 39 & 439 & 17 & 659 \\
\hline $65+$ & 9 & 9 & 25 & 68 & 57 & 50 & 15 & 239 & 472 \\
\hline Total & 1,004 & 479 & 2,025 & 3,094 & 2,198 & 1,402 & 571 & 292 & 11,065 \\
\hline \multicolumn{10}{|c|}{ Injuries } \\
\hline $0-9$ & 25 & 3 & 63 & 180 & 111 & 53 & 22 & 12 & 469 \\
\hline $10-15$ & 79 & 15 & 57 & 143 & 126 & 57 & 16 & 8 & 501 \\
\hline $16-19$ & 693 & 96 & 256 & 221 & 155 & 51 & 26 & 16 & 1,514 \\
\hline 20 & 77 & 184 & 88 & 61 & 30 & 13 & 5 & 5 & 463 \\
\hline $21-24$ & 102 & 69 & 859 & 308 & 129 & 81 & 31 & 11 & 1,590 \\
\hline $25-34$ & 107 & 34 & 262 & 1,187 & 235 & 127 & 73 & 45 & 2,070 \\
\hline $35-44$ & 59 & 27 & 106 & 275 & 573 & 141 & 80 & 31 & 1,292 \\
\hline $45-54$ & 41 & 10 & 75 & 167 & 125 & 250 & 50 & 26 & 744 \\
\hline $55-64$ & 15 & 5 & 35 & 69 & 45 & 50 & 83 & 16 & 318 \\
\hline $65+$ & 12 & 7 & 13 & 38 & 45 & 29 & 15 & 51 & 210 \\
\hline Total & 1,210 & 450 & 1,814 & 2,649 & 1,574 & 852 & 401 & 221 & 9,171 \\
\hline \multicolumn{10}{|c|}{ Noninjury/unknown victimizations } \\
\hline $0-9$ & 5 & 10 & 30 & 109 & 75 & 33 & 30 & 11 & 303 \\
\hline $10-15$ & 23 & 4 & 19 & 52 & 54 & 24 & 11 & 6 & 193 \\
\hline $16-19$ & 121 & 18 & 64 & 78 & 71 & 27 & 19 & 11 & 409 \\
\hline 20 & 10 & 37 & 16 & 25 & 15 & 7 & 5 & 0 & 115 \\
\hline $21-24$ & 40 & 29 & 206 & 134 & 53 & 28 & 31 & 3 & 524 \\
\hline $25-34$ & 34 & 14 & 105 & 427 & 127 & 69 & 45 & 23 & 844 \\
\hline $35-44$ & 26 & 21 & 76 & 151 & 326 & 84 & 49 & 19 & 752 \\
\hline $45-54$ & 23 & 15 & 54 & 108 & 105 & 158 & 38 & 15 & 516 \\
\hline $55-64$ & 10 & 8 & 22 & 48 & 45 & 20 & 66 & 9 & 228 \\
\hline $65+$ & 1 & 6 & 3 & 15 & 28 & 15 & 11 & 39 & 118 \\
\hline Total & 293 & 162 & 595 & 1,147 & 899 & 465 & 305 & 136 & 4,002 \\
\hline
\end{tabular}

Source: Author tabulations from FARS (2009) case listings. See Methods. 
Table 2

Age group of drinking driver in fatal crash by age group of victim and person type, California, 1998-2007

\begin{tabular}{|c|c|c|c|c|c|c|c|c|c|}
\hline \multirow[b]{2}{*}{ Victim age } & \multicolumn{9}{|c|}{ Intoxicated driver age } \\
\hline & $<20$ & 20 & $21-24$ & $25-34$ & $35-44$ & $45-54$ & $55-64$ & $65+$ & Total \\
\hline \multicolumn{10}{|c|}{ Drivers } \\
\hline $0-9$ & 1 & 0 & 0 & 0 & 0 & 0 & 0 & 0 & 1 \\
\hline $10-15$ & 11 & 0 & 1 & 0 & 2 & 1 & 0 & 0 & 15 \\
\hline $16-19$ & 829 & 10 & 62 & 85 & 64 & 40 & 24 & 13 & 1,127 \\
\hline 20 & 14 & 413 & 24 & 33 & 29 & 18 & 8 & 4 & 543 \\
\hline $21-24$ & 43 & 25 & 1,817 & 154 & 96 & 54 & 37 & 11 & 2,237 \\
\hline $25-34$ & 65 & 25 & 171 & 2,968 & 195 & 116 & 83 & 47 & 3,670 \\
\hline $35-44$ & 51 & 38 & 153 & 298 & 2,208 & 130 & 90 & 36 & 3,004 \\
\hline $45-54$ & 61 & 24 & 110 & 234 & 165 & 1,365 & 53 & 26 & 2,038 \\
\hline $55-64$ & 25 & 15 & 57 & 107 & 78 & 55 & 545 & 16 & 898 \\
\hline $65+$ & 11 & 13 & 20 & 57 & 54 & 36 & 15 & 276 & 482 \\
\hline Total & 1,111 & 563 & 2,415 & 3,936 & 2,891 & 1,815 & 855 & 429 & 14,015 \\
\hline \multicolumn{10}{|c|}{ Passengers } \\
\hline $0-9$ & 37 & 18 & 108 & 365 & 225 & 94 & 56 & 24 & 927 \\
\hline $10-15$ & 133 & 28 & 90 & 218 & 202 & 88 & 33 & 14 & 806 \\
\hline $16-19$ & 694 & 159 & 375 & 279 & 192 & 62 & 29 & 17 & 1,807 \\
\hline 20 & 97 & 84 & 132 & 82 & 26 & 12 & 5 & 1 & 439 \\
\hline $21-24$ & 159 & 114 & 633 & 461 & 126 & 69 & 30 & 5 & 1,597 \\
\hline $25-34$ & 125 & 45 & 354 & 795 & 265 & 111 & 53 & 24 & 1,772 \\
\hline $35-44$ & 53 & 25 & 108 & 284 & 293 & 141 & 46 & 23 & 973 \\
\hline $45-54$ & 30 & 6 & 58 & 132 & 151 & 129 & 48 & 21 & 575 \\
\hline $55-64$ & 10 & 7 & 25 & 43 & 50 & 47 & 36 & 22 & 240 \\
\hline $65+$ & 9 & 6 & 14 & 40 & 59 & 42 & 17 & 49 & 236 \\
\hline Total & 1,347 & 492 & 1,897 & 2,699 & 1,589 & 795 & 353 & 200 & 9,372 \\
\hline \multicolumn{10}{|c|}{ Pedestrian, bicyclist, other nonoccupant } \\
\hline $0-9$ & 2 & 1 & 7 & 6 & 14 & 6 & 2 & 0 & 38 \\
\hline $10-15$ & 2 & 1 & 7 & 13 & 13 & 7 & 1 & 1 & 45 \\
\hline 16-19 & 8 & 6 & 11 & 26 & 17 & 2 & 2 & 2 & 74 \\
\hline 20 & 2 & 3 & 5 & 4 & 5 & 0 & 1 & 0 & 20 \\
\hline $21-24$ & 3 & 5 & 11 & 30 & 20 & 6 & 3 & 0 & 78 \\
\hline $25-34$ & 13 & 6 & 25 & 55 & 28 & 18 & 10 & 4 & 159 \\
\hline $35-44$ & 11 & 4 & 21 & 42 & 24 & 27 & 20 & 3 & 152 \\
\hline $45-54$ & 3 & 4 & 19 & 38 & 36 & 20 & 14 & 2 & 136 \\
\hline $55-64$ & 3 & 3 & 9 & 17 & 17 & 7 & 7 & 4 & 67 \\
\hline $65+$ & 2 & 3 & 7 & 24 & 17 & 16 & 9 & 4 & 82 \\
\hline Total & 49 & 36 & 122 & 255 & 191 & 109 & 69 & 20 & 851 \\
\hline
\end{tabular}

Source: Author tabulations from FARS (2009) case listings. See Methods.

(mean BAC, 0.154\%; median, 0.143\%) averaged well above the legal intoxication limit $(0.08 \%)$.

Substantially more California teenaged vehicle passengers who were killed, injured, and otherwise victimized in fatal alcohol-related crashes were victims of drinking over-21 adult drivers (645 age 10-15 and 954 age 16-19) than of drinking teenaged drivers (133 age 10-15 and 694 age 16-19). One-fourth of teenage drivers, two-thirds of teen passengers, and five-sixths of teenage pedestrians and cyclists killed in alcohol-related crashes were victims of drinking adult drivers 21 and older (Table 2). Drinking adult drivers at every age level-young adult, middle-aged, and senior (though the over-55 
figures were small) - victimized more teenagers than the other way around. In contrast, drinking teenage drivers caused around $4 \%$ of victimizations of children age $0-9,17 \%$ of youths age $10-15,51 \%$ of $16-19$ year-olds, $11 \%$ of 20 year-olds, and $4 \%$ of adults 21 and older. Drinking 20-year-old drivers, tabulated separately, accounted for a large majority of peer victimizations and small proportions of the victimizations of other ages.

Table 3

Teen/adult and adult/teen drinking-driver fatal crash victimizations by injury severity and person type, California, 1998-2007

\begin{tabular}{|c|c|c|c|c|c|c|}
\hline Total $^{a}$ & Killed & Injured & Noninjury $^{a}$ & Driver & Passenger & Nonoccupant $^{\mathrm{a}}$ \\
\hline \multicolumn{7}{|c|}{ Drinking driver age $16-19$, victim age 15 or younger } \\
\hline 166 & 43 & 96 & 27 & 0 & 165 & 1 \\
\hline \multicolumn{7}{|c|}{ Drinking driver age $16-19$, victim age $16-19$} \\
\hline 1,526 & 716 & 689 & 121 & 829 & 689 & 8 \\
\hline \multicolumn{7}{|c|}{ Drinking driver age 16-19, victim age $21+$} \\
\hline 674 & 206 & 334 & 134 & 256 & 384 & 34 \\
\hline \multicolumn{7}{|c|}{ Drinking driver age $21+$, victim age 15 or younger } \\
\hline 1,598 & 296 & 848 & 454 & 4 & 1,519 & 75 \\
\hline \multicolumn{7}{|c|}{ Drinking driver age $21+$, victim age 16-19 } \\
\hline 1,302 & 307 & 725 & 270 & 288 & 954 & 60 \\
\hline \multicolumn{7}{|c|}{ Drinking driver age $21+$, victim age $21+$} \\
\hline 17,351 & 8,860 & 5,736 & 2,755 & 11,933 & 4,804 & 614 \\
\hline
\end{tabular}

Table 3a

Teen/adult and adult/teen drinking-driver fatal crash victimizations of "innocent victims" by injury severity and person type, California, 1998-2007

\begin{tabular}{|c|c|c|c|c|c|c|}
\hline Total $^{a}$ & Killed & Injured & Noninjury $^{b}$ & Driver & Passenger & Nonoccupant $^{\mathrm{b}}$ \\
\hline \multicolumn{7}{|c|}{ Drinking driver age $16-19$, victim age 15 or younger } \\
\hline 166 & 43 & 96 & 27 & 0 & 165 & 1 \\
\hline \multicolumn{7}{|c|}{ Drinking driver age $16-19$, victim age 16-19 } \\
\hline 717 & 230 & 419 & 68 & 23 & 689 & 5 \\
\hline \multicolumn{7}{|c|}{ Drinking driver age $16-19$, victim age $21+$} \\
\hline 638 & 186 & 321 & 131 & 230 & 384 & 24 \\
\hline \multicolumn{7}{|c|}{ Drinking driver age $21+$, victim age 15 or younger } \\
\hline 1,597 & 295 & 848 & 454 & 4 & 1,519 & 74 \\
\hline \multicolumn{7}{|c|}{ Drinking driver age $21+$, victim age $16-19$} \\
\hline 1,267 & 285 & 715 & 267 & 262 & 954 & 51 \\
\hline \multicolumn{7}{|c|}{ Drinking driver age $21+$, victim age $21+$} \\
\hline 8,443 & 2,506 & 3,925 & 2,012 & 3,195 & 4,804 & 444 \\
\hline
\end{tabular}


Table 3 shows that drinking drivers ages 21 and older victimize nearly twice as many teenagers ages 16-19 $(1,302)$ than the other way around (694), including $12.5 \%$ more drivers. When drinking drivers' victimizations of themselves, other drinking drivers, and drinking pedestrians, cyclists, and other vehicle nonoccupants are eliminated to provide counts only of "innocent" victims (that is, passengers and sober drivers and nonoccupants), drivers age 21 and older victimized 1,597 children and youths under age 16 and 1,267 teens age 16-19 (Table 3a). Counting only innocent victims, drinking teen drivers victimized 166 children age 0-15, 717 peers age 16-19, and 638 age 21 and older.
Of the 12,341 over-21 and the 1,111 teenaged California drinking drivers involved in fatal crashes, $7.1 \%$ and $2.4 \%$, respectively, were listed as having previous convictions for driving while intoxicated; $1.4 \%$ had two or more previous DWIs (not shown). Drivers with previous DWIs had higher BACs (median, $0.21 \%$ ) and caused somewhat deadlier crashes than did drinking drivers with no previous DWIs (median 0.14\%). Comparing fatal alcoholrelated crash involvements in the most recent five years (2003-07) to the first five years (19992002) and adjusting for population changes by age, teenagers and senior citizens showed

Table 4

Estimation procedure to project all annual victimizations of children and teens in alcohol-related crashes by California over-21 drivers, 2000

\begin{tabular}{|c|c|c|c|c|}
\hline \multirow[b]{2}{*}{ Alcohol-related crashes (2000 figures) } & \multicolumn{4}{|c|}{ Alcohol-related crash outcome } \\
\hline & All crashes & Fatal & Injury & Noninjury $^{\mathrm{a}}$ \\
\hline \multicolumn{5}{|c|}{ FARS annual fatal alcohol-related crash counts, drivers age $21+$, victim age $<20$} \\
\hline Victims age $<16$ (average, 1997-2008) & 159.8 & 29.6 & 84.8 & 45.4 \\
\hline Vict & & 30 & & 27.0 \\
\hline All victims age $<20$ & 290.0 & 60.3 & 157.3 & 72.4 \\
\hline \multicolumn{5}{|c|}{ Projection of FARS alcohol-related fatal crash victims to all alcohol-related victims } \\
\hline FARS, alcohol-related victims & & 1,024 & & 365 \\
\hline $\mathrm{NH}$ & $182,($ & 1,401 & & $\mathrm{n} / \mathrm{a}$ \\
\hline Multiplier & 81.0 & 1.37 & 50.2 & $\mathrm{n} / \mathrm{a}$ \\
\hline \multicolumn{5}{|c|}{ Projection, all annual alcohol related crashes, driver age $21+$, victim age $<20^{\mathrm{b}}$} \\
\hline & 12,900 & 40 & 4,300 & 8,600 \\
\hline & & 42 & & 6,900 \\
\hline All victims age $<20$ & 23,500 & 82 & 7,900 & 15,500 \\
\hline \multicolumn{5}{|c|}{$\begin{array}{l}\text { aNoninjury victimizations are not estimated by NHTSA; estimates derive from subtracting fatal and injury } \\
\text { victimizations from totals. Estimates for noninjury victims are subject to considerable uncertainty (see Method). } \\
\text { Columns may not add up due to rounding. } \\
\text { 'Multiplier from NHTSA's estimates for all alcohol-related traffic fatalities for California and for alcohol-related } \\
\text { injuries and PIRE's estimate of all alcohol-related crashes applied to FARS tabulation of deaths and injuries from } \\
\text { alcohol-related fatal crashes. Based on NHTSA state tabulations, California accounted for around } 8.41 \% \text { of the } \\
\text { nation's alcohol-related crashes in 2000. } \\
\text { Sources: FARS (2009); PIRE (2000). }\end{array}$} \\
\hline
\end{tabular}

declines in crash rates, young adults ages 20-34 showed large rate increases (up 24\%), and middle aged groups age 35-64 more moderate increases (up 5\%).

\section{Estimates for nonfatal crashes}

Author calculations based on Pacific Institute for Research and Evaluation estimates for NHTSA (PIRE, 2000), which approximate injury crashes and offer a rough estimate of noninjury crashes, project 235,000 alcohol-related crashes caused by California drinking drivers ages 21 and older that victimized children and teens from 1998 through 2007. These crashes resulted in the deaths of more than 400 children/youths under age 16 and 400 teens age 16-19, injuries to 43,000 children/youths and 36,000 teens, and at least 155,000 noninjury victimizations of 
children, youths, and teens over the 10-year period.

\section{Discussion}

This paper appears the first attempt, at least in California, to quantify the extent to which over21 drinking and driving menaces the underaged. The hypothesis that a large majority of teens in alcohol-related crashes would be victims of peer teen drivers was not sustained. In fact, a large and disproportionate share of what we call "teenage drunken driving" risks are caused by adults older than the legal drinking age. Every year over the last decade, approximately 23,500 motor vehicle crashes causing 82 deaths and 7,900 injuries to California children under age 16 and teens age 16-19 were caused by drinking drivers 21 and older whose blood alcohol levels (median, 0.14\%) averaged well over the legal limit. Although child endangerment laws enhance the penalties for impaired driving while transporting children, the toll of DWI on children remains high. If over-21 drinking and driving were classified as a separate mortality cause in the Centers for Disease Control's 113 Injury Mechanisms and All Other Leading Causes (CDC, 2009, based on 2005 totals), it would rank as the fifth leading cause of death of California teenagers age 16-19 (after all motor vehicle crashes, firearms injury, suffocations, and cancers) and the sixth leading cause of death of California children and youths ages one through 15 (behind all motor vehicle crashes, congenital malformations, cancers, drownings, and heart disease). "Teenage drinking and driving," if classified as a separate mortality cause, also would rank as the fifth leading cause of death of 16-19 year-olds.

One unexpected finding is that more than twice as many teen passengers age 16-19 killed, injured, and otherwise victimized in fatal alcohol-related crashes were victims of drinking over-21 drivers than of drinking teenaged drivers. Half of all teens age 16-19, including drivers, victimized in fatal alcohol-related crashes were victims of drinking drivers aged 20 and older, and $43 \%$ were victims of drinking drivers age 21 and older. Two-thirds of teens victimized by adults were victims of drinking drivers age 25 and older. Further, although normal reciprocity suggests the number of adult drivers victimized by drinking teen drivers should equal the number of teen drivers victimized by drinking adult drivers (in fact, popular views of teens as reckless and inexperienced with motor vehicles and alcohol would suggest drunken teen drivers should victimize more adults), the observed reality is that drinking drivers age 21 and older caused crashes that victimized more teen drivers than the other way around. Further, teenaged drivers' risks, both sober and impaired, are enhanced by their concentration in poorer counties and socioeconomic groups, conditions which are tied to higher crash rates (Males, 2009).

The reality that California children and teenagers pay a heavy price for adults' privilege to consume alcohol recreationally is mentioned occasionally in anti-DWI public service anecdotes but has not been systematically acknowledged in public or policy discussion. Rather, teenagers' alcohol-related traffic crash involvements, deaths, and injuries uniformly are depicted as consequences of "underaged drinking," and when interage victimizations are mentioned at all, teens are more likely to be depicted as menacing innocent adults (i.e., California Highway Patrol, 2009; AAA, 2006; InjuryBoard, 2006; NIAAA, 1997a).

The evidence that drinking adult drivers present a substantial risk to teen drivers, and a greater risk to teen passengers and vehicle nonoccupants than do drinking teen drivers, raises important policy questions. Adult and teenage DWI is not simply mathematically correlated, but form a unified behavior risk. The strong associations between adult and teenage alcohol use and DWI accident risks combined with the high proportions of drinking adult drivers victimizing teenagers argue that reducing "underaged" alcohol-related crashes is tied closely to reducing "overaged" propensities to cause many of these crashes. Rather than targeting "underaged drinking" as a separate issue, then, perhaps officials, safety groups, and the news 
media would better promote driving and alcohol safety by acknowledging the integrated nature of alcohol abuse among all ages.

Existing laws controlling adults' public alcohol abuse have proven inadequate to prevent the alarming toll over-21 adult drinkers inflict on children and teenagers. U.S. and California laws are lenient, allowing adults 21 and older to drive legally with BACs considerably higher than are allowed in most other countries (DSA, 2009), to drive legally with alcohol levels (up to $0.07 \%$ ) associated with crash risks approximately five times higher than for sober drivers (Zador, Krawchuk, \& Voas, 2000), and to continue consuming alcohol legally even after convictions for drunken driving and other alcohol-related offenses. However, reforms, such as tightening
BAC limits necessary to establish DWI from $0.08 \%$ to $0.04 \%$ as recommended by former Surgeon General C. Everett Koop, revoking the privileges of adults convicted of DWI or another serious alcohol-related offense to drink legally, and realigning legal controls on alcohol use to focus less on age than on individually demonstrated records of alcohol abuse are likely to be politically difficult to implement. Disturbingly, the lack of candid discussion and policy proposals by traffic safety officials, health agencies, politicians, and the news media suggests that "overaged" adults' extensive victimization of "underaged" teenagers and children in alcohol-related traffic crashes tacitly is seen as an acceptable price for convenient alcohol access even by irresponsible adult drinkers.

\section{References}

AAA (formerly American Automobile Association) (2006). Teen crashes: Everyone is at risk. People fatally injured in motor vehicle crashes involving 15- to 17-year-olds. Washington, DC: AAA.

Bureau of the Census (2009). State population projections. Available at: http://www.census.gov/population/www/projections/stproj.html. Accessed June 15, 2009.

California Highway Patrol (2009). Every 15 minutes. Sacramento: Department of the Highway Patrol. Available at: http://www.chp.ca.gov/programs/fifteen.html. Accessed July 5, 2009.

CDC (Centers for Disease Control) (2009). WONDER compressed mortality, 1999-2005 request. Available at: http://wonder.cdc.gov/cmf-icd10.html. Accessed July 1, 2009.

CNN (2006). AAA: Stronger laws, parental supervision needed for teen drivers. January 18, 2006. Available at: http://www.cnn.com/2006/US/01/18/cnna.darbelnet/index.html. Accessed March 10, 2009.

DSA (Drive and Stay Alive) (2009). Drunk driving blood alcohol limits worldwide. Available at: http://www.driveandstayalive.com/articles\%20and\%20topics/drunk\%20driving/artcl--drunk-driving0005--global-BAC-limits.htm. Accessed March 10, 2009.

FARS (Fatality Analysis Reporting System) (2009). Fatality analysis reporting system encyclopedia. Washington, DC: National Highway Traffic Safety Administration. Available at: http://wwwfars.nhtsa.dot.gov/QueryTool/QuerySection/SelectYear.aspx. Accessed March 5, and July 1, 2009.

Hawkins, J.D., Graham, J.W., Maguin, E., Abbot, R., Hill, K.G., \& Catalano, R. (1997). Exploring the effects of age of alcohol use initiation and psychosocial risk factors on subsequent alcohol misuse. Journal of Studies on Alcohol, 58(3): 280-290.

InjuryBoard (2006). Teen drivers responsible for 31,000 auto accident deaths. Dallas, TX: InjuryBoard.com. Available at: http://dallas.injuryboard.com/automobile-accidents/teen-driversresponsible-for-31000-auto-accident-deaths.aspx?googleid=201006. Accessed March 10, 2009.

Latendresse, S.J., Rose, R.J., Viken, R.J., Pulkkinen, L., Kaprio, J., and Dick, D.M. (2008). Parenting mechanisms in links between parents' and adolescents' alcohol use behaviors. Alcoholism: Clinical and Experimental Research, 32(2), 322-330.

Males, M. (2009). The role of poverty in California teenagers' fatal traffic crash risk. Californian Journal of Health Promotion, 7(1), in press.

Males, M. (2007). California's graduated driver license law: Effect on teenaged drivers' deaths through 2005. Journal of Safety Research, 38, 651-659. 
Margolis, L.H., Foss, R.D., \& Tolbert, W.G. (2000). Alcohol and motor vehicle-related deaths of children as passengers, pedestrians, and bicyclists. Journal of the American Medical Association, 283:2245-2248.

Masten, S.V., \& Hagge, R.A. (2004). Evaluation of California's graduated driver licensing program. Journal of Safety Research, 35, 523-535.

NCASA (National Center on Addiction and Substance Abuse) (1999). 1999 Survey of American Attitudes and Substance Abuse V: Teens and Their Parents. New York: Columbia University.

NHTSA (National Highway Traffic Safety Administration) (2001). Traffic safety facts 2000. Washington, DC: US Department of Transportation, December 2001.

NIAAA (National Institute on Alcohol Abuse and Alcoholism) (1997). Ninth special report to the U.S. Congress on alcohol and health. Bethesda, MD: U.S. Department of Health and Human Services.

NIAAA (National Institute on Alcohol Abuse and Alcoholism) (1997a). Youth drinking: Risk factors and consequences. Alcohol alert no. 37. Bethesda, MD: U.S. Department of Health and Human Services.

PIRE (Pacific Institute for Research and Evaluation) (2000). Impaired driving in the United States. Washington, DC: National Highway Traffic Safety Administration. Available at: http://www.nhtsa.dot.gov/people/injury/alcohol/impaired_driving_pg2/US.htm. Accessed March 10, 2009.

SAMHSA (Substance Abuse and Mental Health Services Administration) (2009). National household survey on drug use and health. State level data on alcohol, tobacco, and illegal drug use. Bethesda, MD: US Department of Health and Human Services. Available at: http://www.oas.samhsa.gov/2k6state/toc.cfm. Accessed March 10, 2009.

Shults, R.A., Lindsey, T., \& Quinlan, K.P. (2002). Child passenger deaths involving drinking driversUnited States, 1997-2002. Journal of the American Medical Association, 291:934-935.

Zador, P.L., Krawchuk, S.A., and Voas, R.B. (2000). Relative risk of fatal crash involvement by BAC, age, and gender. DOT HS 809 050. Washington, DC: US Department of Transportation.

\author{
Author Information \\ Mike Males, Ph.D.* \\ Senior Researcher \\ Center on Juvenile and Criminal Justice \\ 333 N.W. Fifth Street, \#2006 \\ Oklahoma City, OK 73102 \\ Email:mmales@earthlink.net \\ Phone: (405)219-8539 \\ * corresponding author
}

